\title{
Neuroendocrine responsiveness to oestradiol and male urine in neonatally androgenized prairie voles (Microtus ochrogaster)
}

\author{
L. Smale, R. J. Nelson* and I. Zucker \\ Department of Psychology and Group in Endocrinology, University of California, \\ Berkeley, CA 94720, U.S.A.
}

\begin{abstract}
Summary. The influence of neonatal androgenization on behavioural receptivity was tested by treating female voles on the 3rd day of life with testosterone propionate or with the oil vehicle. After treatment in adulthood with urine or with oestradiol benzoate, androgenized voles were less likely than normal females to display behavioural oestrus and were more likely to engage in agonistic behaviour in tests with stud males. Uteri of androgenized and control females treated with oestradiol benzoate in adulthood manifested similar increases in weight; however, only normal females treated with male urine showed increased uterine weights. Males castrated in adulthood did not display lordosis after treatment with oestradiol benzoate. Sexual differentiation induced by neonatal testicular secretions appears to limit responsiveness of the adult neuroendocrine axis to chemosensory stimuli in male urine.
\end{abstract}

\section{Introduction}

In several mammalian species, females treated with androgens during perinatal development do not manifest normal reproductive cycles or sexual behaviour in adulthood. The phasic release of gonadotrophins characteristic of the normal oestrous cycle is inhibited by perinatal exposure to testosterone in female mice, rats and hamsters (Feder, 1981). Testosterone treatment before or after birth also induces behavioural defeminization in several but not all mammalian species. For example, early androgenization inhibits the expression of receptive behaviour in female rats, hamsters, guinea-pigs, mice, dogs and sheep (Phoenix, Goy, Gerall \& Young, 1959; Grady, Phoenix \& Young, 1965; Beach \& Kuehn, 1970; Edwards \& Burge, 1971; Carter, Clemens \& Hoekema, 1972; Clarke, 1977), but has little or no effect on female sexual behaviour of ferrets, marmosets or rhesus monkeys (Abbott \& Hearn, 1979; Baum \& Gallagher, 1981; Phoenix, Jensen $\&$ Chambers, 1983). Based on these findings Baum (1979) has suggested that testosterone defeminizes only those neural tissues that rely on the synergistic interaction of oestrogens and progesterone for normal function in adulthood. According to this hypothesis neural substrates and behaviours activated by oestradiol alone should not be affected by the perinatal androgenization process.

The prairie vole, Microtus ochrogaster, is unusual among mammals in the extent to which induction of oestrus is dependent on chemosensory stimuli provided by conspecific males (Richmond \& Conaway, 1969). Urine from intact males stimulates release of luteinizing hormone (LH) within 5 min (Dluzen, Ramirez, Carter \& Getz, 1981) and induces uterine growth (Carter, Getz, Gavish, McDermott \& Arnold, 1980) and behavioural oestrus within 2 days (L. Smale, unpublished observations). Females isolated from conspecifics remain permanently non-receptive.

* Present address: Institute of Reproductive Biology, Department of Zoology, University of Texas, Austin, TX 78712 , U.S.A. 
Ovulation in prairie voles is provoked by copulation (Richmond \& Conaway, 1969) and female receptivity is induced by oestradiol alone; progesterone inhibits sexual receptivity (Dluzen \& Carter, 1979). The prairie vole therefore presents a convenient species in which to test Baum's hypothesis (1979) regarding behavioural defeminization by perinatal androgens. According to this model, female prairie voles treated with androgens perinatally, as well as adult males, should retain the ability to display components of female sexual behaviour when treated with oestrogens in adulthood. In the present study we have tested this model. In addition we have examined the possibility that androgenization of females affects neuroendocrine responsiveness to exteroceptive stimuli that bring normal females into oestrus.

\section{General Methods}

Animals. Voles were from locally bred stock derived from a laboratory colony maintained at the University of Illinois, Champaign-Urbana, U.S.A., since 1970 (LS = laboratory strain) or were from a local breeding colony established with animals trapped in south central Illinois in 1983 (WS $=$ wild strain). Animals were kept in a room illuminated for $16 \mathrm{~h}$ daily (lights on at 07:00 $\mathrm{h}$ Pacific Standard Time) and maintained at a temperature of $21^{\circ} \mathrm{C}$. Voles were weaned at 25 days of age and housed thereafter individually in plastic cages $(28 \times 17 \times 12 \mathrm{~cm})$ and provided with Purina Rodent Chow plus Purina Guinea Pig Chow and water ad libitum.

Neonatal treatment. All female young from a given litter were injected subcutaneously at 3 days of age with $0.5 \mathrm{mg}$ testosterone propionate (Sigma Chemical Co., St Louis, MO, U.S.A.) dissolved in $0.05 \mathrm{ml}$ sesame oil or with the same volume of the oil vehicle.

Mating tests. Behaviour was observed between $16: 00$ and 18:00 $\mathrm{h}$ in a clear glass enclosure (26 $\times 50 \times 29 \mathrm{~cm}$ ) filled to a depth of $2 \mathrm{~cm}$ with wood shavings. Preliminary studies as well as chance observations in the breeding colony indicated that prairie voles readily mate during the light phase of the light:dark cycle. A sexually mature adult male was allowed to adapt to this apparatus for 3 min before introduction of the female. The latencies to the first mount, intromission and lordosis were measured to the nearest second and the occurrence of agonistic encounters was recorded.

Hormone assays. Voles were anaesthetized with methoxyflurane (Metofane: Pitman Moore) and a blood sample obtained from the retro-orbital venous plexus (Riley, 1960). Blood was centrifuged immediately and plasma stored frozen until radioimmunoassays (RIA) for LH were performed by an ovine-ovine procedure. This procedure has been validated and used extensively for measurement of plasma $\mathrm{LH}$ in a number of mammalian species, including several rodents (e.g. ground squirrels: Licht, Zucker, Hubbard \& Boshes, 1982; hamsters: Blake, Norman \& Sawyer, 1973; rats: Niswender, Midgley, Monroe \& Reichert, 1968). Anti-ovine serum (GDN No. 15) was provided by Dr Gordon Niswender and highly purified LH (G3-256 DA) for radioiodination of standards was supplied by Dr Harold Papkoff. Four serial dilutions $(0 \cdot 78-25 \mu \mathrm{l})$ of plasma samples in $100 \mu \mathrm{l} 0 \cdot 25 \mathrm{M}$-potassium phosphate buffer (K-PB) were incubated for $24 \mathrm{~h}$ at $4^{\circ} \mathrm{C}$ with $50 \mu \mathrm{l}$ antiserum $\left(1: 18000\right.$ in K-PB). ${ }^{125}$ I-labelled ovine $\mathrm{LH}(50 \mu \mathrm{l}$ in K-PB) was added for an additional $24 \mathrm{~h}$ before introduction of $100 \mu \mathrm{l}$ of the second antibody (goat anti-rabbit) for separation of bound and free hormone. Antiserum and tracer were diluted in $0.25 \mathrm{M}$-potassium phosphate buffer. Bound hormone (precipitate) was counted in a Micromedic (4/200 plus) Gamma Counter. Potencies were expressed in terms of $\mathrm{ng}$ equivalents of purified $\mathrm{LH}(\mathrm{G} 3-256 \mathrm{DA}) / \mathrm{ml}$ plasma. The minimal detectable level of LH in vole plasma was $1 \mathrm{ng} / \mathrm{ml}$. Inhibition curves for vole samples were parallel to the ovine standard. A separate test showed that castration caused a significant rise in immunoreactive L.H (up to a 40-fold increase). All samples were measured in the same assay which yielded a variation of $10 \cdot 7 \%$. Computation of potencies was performed using a log-logit computer program. 
Statistical analysis. Differences between groups were evaluated with the appropriate analysis of variance, two-tailed $t$ tests for independent samples or with the $\chi^{2}$ test.

\section{Detailed Methods and Results}

\section{Experiment 1: behavioural oestrus in androgenized females}

Methods. Voles (LS) were injected with testosterone propionate or with oil at 3 days of age. At 45 days of age a blood sample was obtained at 13:00 h. At 15:00 h on the next day urine was collected with a pipette from sexually mature adult males and pooled. One drop of pooled fresh urine was applied to the external nares of each female. Urine treatment continued for 6 consecutive days. A second blood sample was obtained at 13:00 h on the 7th day. After $24 \mathrm{~h}$ females were given the standardized mating test for $15 \mathrm{~min}$; 10-min mating tests were given at 48 and $96 \mathrm{~h}$.

Results. Neonatal treatment with testosterone propionate decreased the effectiveness of male urine in inducing oestrous behaviour. Only 3 of $13(23 \%)$ androgenized females as compared to 6 of $8(75 \%)$ oil-treated controls displayed lordosis during the 3 mating tests $\left(\chi^{2}=4.85 ; P<0.05\right)$. Amongst sexually receptive voles the latency to the first lordosis did not differ as a function of neonatal hormone treatment. Androgenized and control females engaged in $14.4 \pm 2.4$ (s.e.m.) and $6.7 \pm 3.0$ agonistic encounters with stud males over the course of the 3 mating tests $(P<0.05)$.

Before treatment with male urine, plasma LH concentrations were similar for voles in both groups $(40.4 \pm 10.3$ and $44.5 \pm 6.1 \mathrm{ng} / \mathrm{ml}$ for 13 testosterone and 8 oil-treated animals, respectively). After 6 days of treatment with male urine, $\mathrm{LH}$ values increased in oil-treated voles and decreased in testosterone-treated animals (to $48.9 \pm 11.8(\mathrm{~N}=12)$ and $36.0 \pm 6.1(\mathrm{~N}=8)$ $\mathrm{ng} / \mathrm{ml}$, respectively); however, neither the difference between the groups, nor the change in LH concentrations achieved statistical significance.

\section{Experiment 2: uterine weights in androgenized females}

Methods. In Study 1, animals (WS) injected with testosterone propionate on the 3rd day of life and control females not injected at this time were ovariectomized at 60 days of age. Beginning 3 weeks later animals were injected for 4 consecutive days with $0.5 \mu \mathrm{g}$ oestradiol benzoate (Sigma) dissolved in $0.1 \mathrm{ml}$ sesame oil or with the oil vehicle. On the 5th day animals were killed and the uteri were dissected and weighed to the nearest $0.1 \mathrm{mg}$.

In Study 2, a second cohort of females (WS), treated with testosterone or oil on the 3rd day of life, was used to assess the influence of male urine on uterine weight. Some of the females were maintained until 21 days of age in an $8 \mathrm{~h}$ light:16 h dark photoperiod and were housed in the standard 16L:8D photoperiod thereafter. Beginning at 70 days of age, one drop of freshly collected male urine or a drop of tap water was applied for 6 consecutive days to the external nares of females. Vaginal patency was monitored daily thereafter. On the 7 th day animals were given one 15-min mating test and then killed. Uteri were dissected and weighed.

Results. In Study 1, hormone treatment in adulthood affected uterine weight $(\mathrm{F}=60 \cdot 1, P<$ $0.001)$ but neonatal hormone manipulation was without effect $(F=1 \cdot 1)$. Uteri of animals injected with oil for 4 days in adulthood weighed $18.8 \pm 4.2 \mathrm{mg}$ (controls, $\mathrm{N}=4$ ) and $15.4 \pm 2.0 \mathrm{mg}$ (testosterone treated, $\mathrm{N}=6$ ). Animals treated with oestradiol benzoate for 4 days in adulthood had uteri weighing $50.1 \pm 4.0 \mathrm{mg}$ (controls, $\mathrm{N}=4$ ) and $57.7 \pm 9.5 \mathrm{mg}$ (testosterone-treated, $\mathrm{N}=5$ ). Uteri of androgenized and normal females therefore responded similarly to oestradiol benzoate treatment in adulthood.

In Study 2, voles were categorized on the basis of uterine weight as 'reproductive' (uteri $>30$ $\mathrm{mg}$ ) or 'non-reproductive' (uteri $<24 \mathrm{mg}$ ). These weight criteria were chosen because all 7 animals with uteri $>30 \mathrm{mg}$ also had a perforate vagina and all were behaviourally receptive on the day of autopsy; only 3 of 35 voles with uteri $<24 \mathrm{mg}$ had a perforate vagina (none of these 3 was 
behaviourally receptive) and only 1 vole with a closed vagina was behaviourally receptive. No animals had uteri weighing between 24 and $30 \mathrm{mg}$.

A greater proportion of oil-treated $(6 / 12)$ as compared to androgenized females $(0 / 11)$ were 'reproductive' after treatment with urine in adulthood $\left(\chi^{2}=6.03, P<0.05\right)$. Urine $(0 / 11)$ was no more effective than water $(0 / 8)$ in rendering androgenized voles 'reproductive'. However, urine was more effective than water in stimulating reproductive condition in the oil-treated females; $6 / 12$ and $1 / 11$ of these voles were 'reproductive' after urine and water treatment, respectively $\left(\chi^{2}=5 \cdot 31\right.$, $P<0.05)$.

\section{Experiment 3: oestrus in androgenized females treated with oestradiol}

Methods. Androgenized and oil-injected voles from Exp. 1 were used after a 10-day rest period. Animals were weighed, anaesthetized and ovariectomized. Anaesthesia consisted of a mixture of $50 \mathrm{mg}$ ketamine/kg body weight (Vetalar: Parke Davis, Morris Plains, NJ), $5 \mathrm{mg}$ xylazine/kg (Haver-Lockhart, Shawnee, KN) and $5 \mathrm{mg}$ acepromazine/kg (Aveco, Co., Inc., Fort Dodge, IA). After 10 days the voles were given a 10 -min mating test; 24 h later voles received the first of 4 daily s.c. injections of $0.5 \mu \mathrm{g}$ oestradiol benzoate dissolved in $0.1 \mathrm{ml}$ sesame oil. A blood sample was taken $24 \mathrm{~h}$ after the last injection and $24 \mathrm{~h}$ later another series of 3 mating tests, separated by intervals of $48 \mathrm{~h}$, was performed.

Results. None of the ovariectomized voles was in oestrus before treatment with oestradiol benzoate and stud males rarely attempted to mount these animals. After oestradiol treatment 2 of 11 androgenized voles $(18 \%)$ as compared to 5 of 6 oil-treated females $(83 \%)$ displayed lordosis $\left(\chi^{2}\right.$ $=6.70, P<0.01$ ). Stud males attempted to mount $55 \%$ of the androgenized and $83 \%$ of the nonandrogenized females treated with oestradiol. This difference was not statistically significant. The groups did not differ with respect to body mass at the time of ovariectomy.

\section{Experiment 4 : behavioural response to oestradiol in male voles}

Methods. Male and female adult voles (WS) were gonadectomized under anaesthesia (ketamine-xylazine-acepromazine). After a 2-week recovery period each vole was injected once daily for 4 consecutive days with $0.5 \mu \mathrm{g}$ oestradiol benzoate. At $24 \mathrm{~h}$ after the last injection animals were observed in the standardized mating test for $15 \mathrm{~min}$ and $48 \mathrm{~h}$ later were given a second 10 -min test. The entire procedure was repeated twice more with 1 -week intervening between the last mating test and the first injection of the next series.

Results. The lordosis response was manifested at least once by all 7 ovariectomized females during behavioural testing but was never displayed by any of the 12 castrated males $\left(\chi^{2}=19 \cdot 0 ; P\right.$ $<0.001)$. Stud males attempted to mount $92 \%$ of the oestrogen-treated gonadectomized males; the latter fought with the stud males $7.8 \pm 1.8$ times over the course of testing as compared to $2.0 \pm 0.8$ fights per female with the stud males $(P<0.05)$.

\section{Discussion}

The presence of androgens early in life decreases oestrous behaviour and increases agonistic behaviour in adult prairie voles. Androgenized females were less likely than oil-treated controls to display receptive behaviour when treated with male urine. The process of sexual differentiation ordinarily induced by testicular secretions during perinatal development may limit responsiveness of the adult neuroendocrine axis of chemosensory stimuli in male urine. In androgenized females, therefore, urine from males may be less effective in stimulating pituitary gonadotrophin release and consequently circulating oestrogen concentrations may be lower in the androgenized than in the normal female. This might account for differences in receptivity between androgenized and nonandrogenized animals. A second possibility is that perinatal androgenization reduces sensitivity to 
oestradiol in neural substrates that mediate female sexual behaviour. Evidence was obtained in favour of each of these mechanisms.

Differential effects of male urine on gonadotrophin secretion of control and androgenized females were not apparent in this study. Such effects might have been observed if FSH and LH concentrations had been measured $30 \mathrm{~min}$ after application of male urine (see Dluzen et al., 1981) rather than at the end of 6 days of treatment.

The data on uterine weight provide more substantial support for the hypothesis that perinatal androgenization interferes with neuroendocrine responsiveness to oestrus-inducing substances in male urine. Since uteri of androgenized and control females were equally responsive to a standard oestradiol stimulus, this measure provides an index of oestrogen availability in both groups. It is likely that had exposure to male urine stimulated equal oestrogen secretion in androgenized and normal females this would have been reflected in equal uterine weights in the two groups. However, uteri of androgenized voles did not increase in weight after 6 days of treatment with male urine; this same treatment resulted in more than doubling of uterine weight in normal females. Presumably, neonatal androgenization compromises oestrogen secretion in response to male urine. However, in the absence of direct measurement of oestrogen concentrations this conclusion must remain tentative.

Perinatal androgenization also reduces behavioural responsiveness of female voles to oestradiol. Oestrogens more readily stimulated sexual receptivity in normal than in androgenized females. This result is inconsistent with Baum's (1979) prediction that androgens only defeminize neural tissues that require synergistic action of oestrogens and progesterone. In ovariectomized prairie voles progesterone does not facilitate receptive behaviour (Dluzen \& Carter, 1979). However, our conclusions must be qualified by the unexplored possibility that adrenal progesterone normally synergizes with oestrogens to stimulate female sexual behaviour.

Neonatal androgenization produces behavioural defeminization in female hamsters although adult male hamsters treated with oestradiol display the full lordosis response (Eaton, 1970; Carter et al., 1972). Male hamsters normally may not secrete sufficient testosterone during the sensitive perinatal period to affect tissues that mediate female sexual behaviour. In contrast, adult castrated prairie voles treated with oestradiol are not receptive to mounting attempts by stud males and never assumed the lordosis posture. These findings indicate that male voles normally are behaviourally defeminized by their own testicular secretions. In this respect voles are similar to rats and mice. The findings of A. A. Gerall, B. G. Haynie, A. M. B. McDonald \& C. S. Carter (unpublished observations) on sexual differentiation in prairie voles are consistent with the observations reported herein.

Oestradiol enhances attractiveness (see Beach, 1976) in voles regardless of perinatal hormone exposure or treatment. Stud males showed little interest in and never attempted to mate with normal or androgenized ovariectomized females; when these females or gonadectomized males were treated with oestradiol for 4 days in adulthood, their attractiveness increased, as indicated by the number of mounting attempts elicited from stud males. Oestradiol increases attractiveness by means yet to be identified but presumably involves changes in chemosensory properties of the female.

Although the mechanisms for induction of oestrus appear to be qualitatively different in prairie voles from those in a number of other rodents, the process of sexual differentiation of behaviour as first described by Phoenix et al. (1959) applies to voles of this species and presumably to other members of the genus Microtus.

This research was supported by Grant HD-02982 and by NIMH Traineeship MH-15860. We thank Leah Gavish and Lowell Getz, University of Illinois, for providing breeding stock; Guylaine Hubbard and Paul Licht for the radioimmunoassays; Tom Shinder, Lisa Higa, Earl Moore, Nute Gardner, Edgar Nealy and Janet Young for technical assistance; and Maxwell Redfearn of the Division of Animal Resources, University of California, Berkeley, for the use of animal space. 


\section{References}

Abbott, D.H. \& Hearn, J.P. (1979) The effects of neonatal exposure to testosterone on the development of behaviour in female marmoset monkeys. In Sex Hormones and Behatiour (Ciba Fdn Symp., No. 62), pp. 299-316. Excerpta Medica, Amsterdam

Baum, M.J. (1979) Differentiation of coital behaviour in mammals: a comparative analysis. Neurosci. Biobehat: Ret. 3, 265-284.

Baum, M.J. \& Gallagher, C.A. (1981) Increasing dosages of estradiol benzoate activate equivalent degrees of sexual receptivity in gonadectomized male and female ferrets. Physiol. Behav. 26, 751-753.

Beach, F.A. (1976). Sexual attractivity, proceptivity and receptivity in female mammals. Horm. Behar. 7, 105 138.

Beach, F.A. \& Kuehn, R.E. (1970) Coital behavior in dogs. X. Effects of androgenic stimulation during development on feminine mating responses in females and males. Horm. Behat. 1, 347-367.

Blake, C.A., Norman, R.L. \& Sawyer, C.H. (1973) Validation of an ovine-ovine LH radioimmunoassay for use in the hamster. Biol. Reprod. 8, 299-305.

Carter, C.S., Clemens, L.G. \& Hoekema, D.G. (1972) Neonatal androgen and adult sexual behavior in the golden hamster. Physiol. Behav. 9, 89-95.

Carter, C.S., Getz, L.L., Gavish, L., McDermott, L. \& Arnold, P. (1980) Male-related pheromones and the activation of female reproduction in the prairie vole (Microtus ochrogaster). Biol. Reprod. 23, 1038-1045.

Clarke, I.J. (1977) The sexual behaviour of prenatally androgenized ewes observed in the field. $J$. Reprod. Fert. 49, 311-315.

Dluzen, D.E. \& Carter, C.S. (1979) Ovarian hormones regulating sexual and social behaviors in female prairie voles, Microtus ochrogaster. Physiol. Behav. 23, 597-600.

Dluzen, D.E., Ramirez, V.P., Carter, C.S. \& Getz, L.L. (1981) Male urine stimulates localized and opposite changes in luteinizing hormone-releasing hormone and norepinephrine within the olfactory bulb of female prairie voles. Science, N.Y. 212, 573-574.
Eaton, G. (1970) Effect of a single prepubertal injection of testosterone propionate on adult bisexual behavior of male hamsters castrated at birth. Endocrinology 87, 934-940.

Edwards, D.A. \& Burge, K.G. (1971) Early androgen treatment and male and female sexual behavior in mice. Horm. Behat. 2, 49-58.

Feder, H.H. (1981) Perinatal hormones and their role in the development of sexually dimorphic behaviors. In Neuroendocrinology of Reproduction, pp. 127-157. Ed. N. T. Adler. Plenum Press, New York.

Grady, K.L., Phoenix, C.H. \& Young, W.C. (1965) Role of the developing rat testis in the differentiation of the neural tissues mediating mating behavior. $J$. comp. Physiol. Psychol. 59, 176-182.

Licht, P., Zucker, I., Hubbard, G. \& Boshes, M. (1982) Circannual rhythms of plasma testosterone and luteinizing hormone levels in golden-mantled ground squirrels (Spermophilus lateralis). Biol. Reprod. 27, 411-418.

Niswender, G.D., Midgley, A.R., Jr, Monroe, S.E. \& Reichert, L.E., Jr (1968) Radioimmunoassay for rat luteinizing hormone with antiovine $\mathrm{LH}$ serum and LH-131I. Proc. Soc. exp. Biol. Med. 128, 807-811.

Phoenix, C.H., Goy, R.W., Gerall, A.A. \& Young, W.C. (1959) Organizing action of prenatally administered testosterone propionate on the tissues mediating mating behavior in the female guinea pig. Endocrino$\log _{1}$ 65, 369-382.

Phoenix, C.H., Jensen, J.N. \& Chambers, K.C. (1983) Female sexual behavior displayed by androgenized female Rhesus macaques. Horm. Behav. 17, 146-151.

Richmond, M. \& Conaway, C.H. (1969) Induced ovulation and oestrus in Microtus ochrogaster. J. Reprod. Fert., Suppl. 6, 357-376.

Riley, V. (1960) Adaptation of orbital bleeding technic to rapid serial blood studies. Proc. Soc. exp. Biol. Med. 104, 751-754.

Received 10 September 1984 